\title{
SCIENCE
}

A WEEKLY JOURNAL DEVOTED TO THE ADVANCEMENT OF SCIENCE, PUBLISHING THE OFFICIAL NOTICES AND PROCEEDINGS OF THE AMERICAN ASSOCIATION FOR THE ADVANCEMENT OF SCIENCE

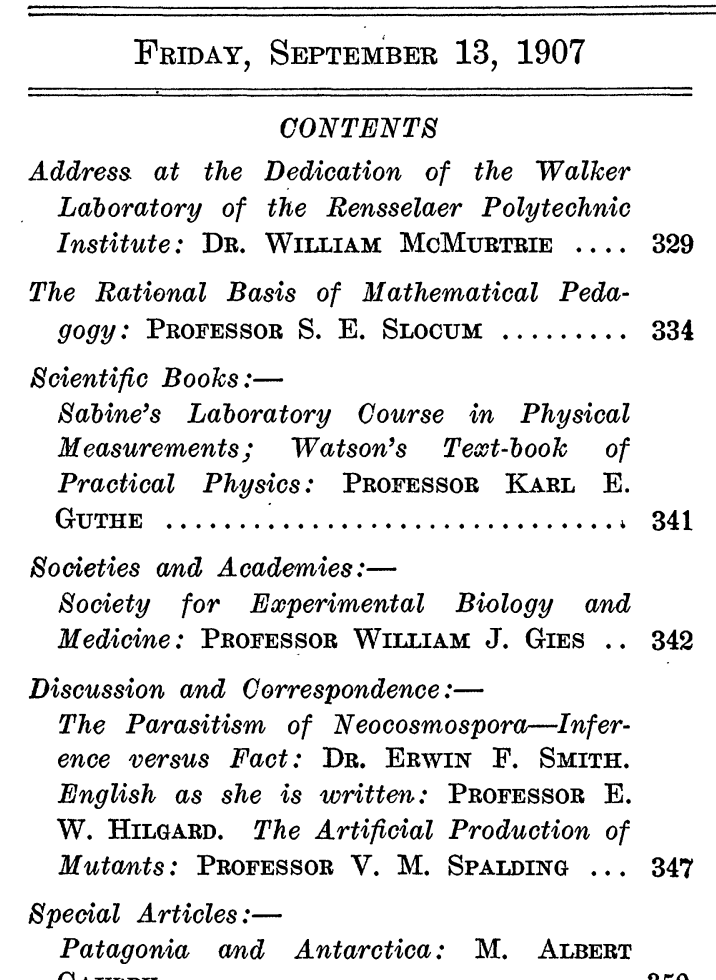

Quotations:-

The Physician in the School 350

Current Notes on Land Forms:Otago Peninsula, New Zealand; The Fayûm Depression, Egypt; The Arid Cycle in Egypt: W. M. D. ............... 353

International Conference on Plant Hardiness and Acclimatization ................ 356

The British Museum ................ 357

Scientific Notes and News ............ 358

University and Educational News ........ 360

MSS. Intended for publication and books, etc., intended for review should be sent to the Editor of ScIrivce, Garrison-onHudson, N. Y.
ADDRESS AT THE DEDICATION OF THE WALKER LABORATORY OF THE RENSSELAER POLYTECHNIC INSTITUTE

I CONSIDER it an honored privilege to be allowed to take part in the ceremony of dedication of this beautiful building devoted to the study and promotion of the science of chemistry in its application to the arts and industries. In this connection it behooves us I think to consider briefly the history of the movement which brings us together, to ponder the purposes of the great institute, of which the work to be done in this building constitutes an integral and important part.

Thinking over what I might be able to present on this occasion it occurred to me to make some inspection of the historic archives of the city of Troy, particularly as they relate to the founding of this, which has taken such a proud position among the educational institutions of the world. In my search I learned that in 1823 Hon. Stephen Van Rensselaer made, most wisely in his lifetime, provision for a school to be located on the outskirts of the city of Troy to be known as the Rensselaer School, and the history of this fact written by Weise offers a copy of the first circular issued to announce that the institution was ready for practical operation, as follows :

Hon. Stephen Van Rensselaer having established a school near the northern limits of Troy for teaching the physical sciences with their applications to the arts of life, having appointed Professors A. S. Eaton and L. C. Beck to give courses of instruction, particularly calculated to prepare 
operative chemists and practical naturalists properly qualified to act as teachers in villages and school districts; having appointed an agent and furnished him with funds for procuring apparatus and fitting up laboratories and a library room, etc., and the agent having given notice to the president of the institution that the requisite collections and preparations are completed, it seems proper to give public notice of the circumstances. Accordingly, the public is respectfully notified that everything is in readiness at the Rensselaer School for giving instruction in chemistry, experimental philosophy and natural history, with their applications to agriculture, domestic economy and the arts, and also for teaching land surveying and all the branches of learning set forth in the circular which was issued in November last, subscribed by the founder and by the president and secretary of the board of trustees. The first term will commence, according to the appointment of the founder, on the first Monday in January, 1825, and continue fifteen weeks.

An evening course by the senior professor in chemistry and experimental philosophy will commence on the third Wednesday in January and continue, three lectures a week, for ten weeks.

(Signed) SAMUer BratchFoRd

Rensselaer School, December 28, 1824.

And so the school was launched, to provide for the study of chemistry, experimental philosophy and natural history with their applications to agriculture, domestic economy and the arts and for teaching land surveying and other branches of learning set forth in this circular. What prophetic vision Van Rensselaer possessed! He saw among other things the importance of liberal education to the life work of every man, and so provided for, in addition to the professional or technical branches of study, training in other branches of learning, presumably the culture studies, essential to the training of every educated man. But note further, that special provision was made first, for the study of chemistry; then for the study of experimental philosophy, or what we now know as physies; and after that natural history, or what we now class generally as biology. These three, chemistry, physics and biology; what better, could have, then or now, been imagined for the broad training of one who should make a life work of the essential arts of life? Van Rensselaer had trouble also to sharply differentiate between chemistry and physics and to give one precedence over the other. For as chemistry applied in the arts is chemical technology, so physics applied in the arts, in a large way, is engineering; and as the dividing line between chemistry and physics is obscure, so, as Van Rensselaer, even in his day, recognized, chemistry and engineering must go hand in hand if progress in the arts is to be assured.

No better illustration of this is to be found than appears around us here. We stand to-day upon historic ground. Here the great engineer Ericsson found his first financial encouragement and support at the hands of those captains of industry and finance, Griswold and Winslow. Encouraged and guided by these master minds, Ericsson was able to complete the historic Monitor and make the white squadron possible. Here was the cradle of the Bessemer process, which made the steel industry of the United States possible and enabled our country to develop the great United States Steel Corporation and lead the world in the manufacture of steel.

There are those, doubtless, who will question what I have just said regarding the priority of Troy in the effective estab, lishment of the Bessemer process for manufacture of steel, but such high authority as R. W. Hunt, one of the pioneers in the industry in this country, says ("Life of Sir Henry Bessemer," Sibley Journal of Engineering, 1904, 161): "Hence the honor of the first heat of Bessemer steel in America belongs to the Wyandotte Works." But he also said (History of the Bessemer Steel Manufac- 
ture in America, American Institute of Mining Engineers, Vol. V., 1876-1877) : "While at the Wyandotte Works steel was made at an earlier date, the Troy establishment was the first to bring the process to a commercial success."

A great chemist once said that the measure of a nation's civilization is its consumption of soap. While this has in the passing years lost none of its truth, the more modern expression becomes-the measure of a nation's civilization is its consumption of fuel and its production and utilization of steel. This is a measure of the supremacy of the United States and we may be proud to-day that we stand in the cradle of the industry which makes this declaration effective. For history tells us that Holley, returning from a trip abroad, where he had made a study of the new and recent discovery of Sir Henry Bessemer and Mushet, associated with him the two enterprising and farsighted gentlemen already mentioned, Griswold and Winslow, in the establishment of the new process on American soil at Troy. As Bessemer had worked out the physical and engineering part of the work, Mushet had seen and worked out the chemical part of the process, and thus made perfection possible. Chemistry and engineering working together, moving forward hand in hand, had brought forth this realization of the greatest step in the world's progress.

What a splendid illustration of the suggestion of the great Tyndall, "the scientific use of the imagination." The imagination of Bessemer saw the possibilities of the new process and the means whereby it could be carried out mechanically; the imagination of Mushet saw the chemical difficulties in the way of ultimate successful operation and how they should be removed. Holley, after the installation of the process on the soil of the United States, saw in imagination the changes necessary to the more perfect realization of the dreams of Bessemer and gave to the industry an impetus which carried it with a terrific rush throughout the length and breadth of our land. For the knowledge and experience of Bessemer were limited to mechanics and engineering. $\mathrm{He}$ had noticed that a blast of air across a bath of molten iron changed the physical properties of the product to those of wrought iron and steel. He saw in the old puddling process the importance of access of air to the molten metal to effect the necessary change in its physical properties to change it to wrought iron and steel. His imagination showed him the possibility of improved mechanical means for effecting these necessary changes by a blast of air through the hot metal, but his imagination was limited by his knowledge and it was not possible for him to determine when his treatment should be stopped. The knowledge of chemistry of Mushet told him that oxidation of the carbon was the cause of the change in physical properties already noted and his imagination led him to the thought that the practical end of Bessemer's process, to get exact results, would be to burn away all the carbon of the iron and add afterward to the bath a definite quantity of carbon, dependent upon the quality of steel desired. So he devised the addition of spiegeleisen at the end of the blow, when the flame of carbon had disappeared from the mouth of the converter, the addition of a substance rich in carbon to supply this essential element, accompanied by manganese capable of reducing the iron oxidized in the converter after oxidation of the carbon of the original iron, and so to relieve the steel of the "shortness" so fatal to its future use. The Bessemer steel process must have, therefore, chemical control as well as engineering direction. 
The necessity Van Rensselaer saw has been realized, and his munificence has made just such combinations possible. The imaginations of Holley and Roebling and Collingwood and Boller and Hodge have made possible the wonderful bridges spanning the great rivers of the world, the network of railroads stretched across the continent, which insures transportation and commerce, but the products which afford realization of these imaginations must have the care and control of the chemist from the earth, from which the raw material sprung, to the wires and bars which constitute the great structures which excite wonder and admiration.

But the founder of the institute saw more in the arts of life. He saw necessity for provision for the immediate wants of mankind, the food and raiment, the removal and utilization of wastes, and if the former may seem to have been neglected by the institute, the latter surely have not. Here is another measure of the civilization of a nation, the utilization of its wastes. Nowhere in the world, perhaps, has this had more intelligent and effective study than in the department of chemistry of the institute. The purity and abundance of the domestic water supply and the healthful and economic disposal of human wastes have in all ages of the world been of the highest public importance. The function of the municipal engineer has been called into activity, and the world is beginning to reap the fruits of its practical application. It is not always true that "fools rush in where angels fear to tread," but rather that wisdom of knowledge courageously leads in untried paths where ignorance blindly follows. The known leads to the unknown. The present builds upon the experience of the past. It is thus that knowledge brings progress, and study, however obscure, brings help and comfort to mankind.

The value of the special knowledge of natural forces and their laws, which Van Rensselaer foresaw, is coming to be more and more appreciated in the commercial world. During the present year the most important representative of the financial interests, The Wall Street Journal, said, editorially, under the caption "Science as a Financial Asset,' inspired doubtless by the address lately delivered by Dr. A. D. Little, of Boston, before the American Chemical Society in annual meeting:

Science as a source of strength in promoting private wealth and public welfare is the one thing that draws the line of demarkation between ancient and modern times. That was a belated medieval, not a modern, outburst of popular wrath against which Lavoisier's friends appealed for his life on the ground of his scientific service to the French state. The powers then in control replied that "the republic had no use for chemists." Far more like modernity is the declaration of a German chemist that "scientific research is the greatest financial asset of the fatherland." Germany's economic progress proves that he was at least much nearer right. The sciences in general have been among the greatest emancipating forces, because they have helped to overcome man's fear of nature, which kept him from utilizing the forces of the world about him, and because they disclosed elements of the highest value to the world in their most practical forms: It has been well said "that if we were to take away what the chemists have contributed, the whole structure of modern society would break down at once. Every commercial transaction in the civilized world is based on the chemist's certificate as to the fineness of gold, which forms our ultimate measure of values. Faith may remove mountains, but modern society relies on dynamite. Without explosives our great engineering works must cease and the Panama Canal, no less than modern warfare, become impossible."

The late Abraham S. Hewitt estimated that the Bessemer process of manufacturing steel added directly and indirectly two thousand million dollars a year to the world's wealth. Bessemer him. self retained only about ten million dollars out of 
this total annual increment. Without chemistry no such dreams could have been realized. Chemistry has made possible the transportation systems which span the leading countries of the world. It has made it possible to turn to man's service the wealth of the mineral world. By analysis of plants and soils, the waste materials of the world have been brought to the growing of crops. Indeed, every great industry, whether it be farming, manufacturing, transportation or mining, would almost immediately relapse to barbarism if the secrets of the chemist and physicist, the geologist and mineralogist could be gathered up and cast into the sea.

The work of science which probably needs most development in the present day, however, is not so much the application of knowledge already acquired to the increase of wealth as the promotion of research in fields whereby the enormous wastes may be checked and the utilized resources of the world immediately around us be won for man's uses. Fundamental research is by far our greatest need. Common clay is full of a commodity which, if it could only be extracted economically, would probably solve for centuries the question of a metal supply for a large part of the needs of mankind.

It was this thought that led an American journal to say that the accidental killing of Professor Curie, the discoverer of radium, in the streets of Paris last April, was a greater loss to the world than the earthquake in San Francisco, where more than a thousand people lost their lives, a quarter of a million persons were rendered homeless by conflagration and property losses estimated at $\$ 500,000,000$ occurred. If that be true, it is neither numbers nor wealth, but scientific talent that gives the power of mastery to nations because of its capacity to unlock the secrets of nature, in which are hid the sources of material welfare.

These are words which must bring much of both comfort and encouragement to those who are just entering upon their life work, as well as to those who have had to work and answer the hard questions offered by the industries. Knowledge is a good financial asset, but it must be exact and accurate knowledge. The hard questions submitted to the educated technologist must be answered promptly but accurately.
And many, if not most, of the questions now pressing for answer are as much chemical as mechanical. For instance, who shall answer the question as to the cause of, and remedy for, the broken rail? Shall it be the engineer or the chemist? Shall the answer be found in the intense speed and the overload of trains, or in the excess of carbon necessary to provide resistance to wear rail surface, or made necessary by an overweening desire to increase tonnage at expense of quality? or shall it be found in the nitrogen introduced in the steel and now found like phosphorus, to have a profound influence upon the physical property of the product? The world, and particularly the United States, is looking anxiously for the correct answer to this question. Will Troy and her men rise to the situation and now, as in the decade ' 65 to '75, bring forth a new Bessemer process to supply the new demand? There are those here present, no doubt, who will take inspiration from this question and do their share to supply this instant demand and do it thoroughly. It is for this that the Rensselaer School was founded, and the Walker laboratory generously provided. And failure and disappointment are surely words which do not belong in the local vocabulary.

The value of the study of chemistry in the training of educated technical men has been realized since the time of Van Rensselaer as well as before. In his address on "The Functions of Technical Education" the late Professor Thurston said: "When the pupil is to go directly into business and his precise line of work is not settled, or when it is evident that he is of that large class in this country liable to pass from one vocation to another, the technical studies for the curriculum should be in general, mathematics and the science of physics and particularly of chemistry." 
This dictum from the great head of the, Sibley School of Engineering is impressive and worthy of careful consideration. It fully justifies our presence here to-day for the purpose in hand and confirms the judgment of the founder of this institute and the purpose of the generous donors of the Walker Laboratory we here and now dedicate to the study of chemistry.

We may heartily join in congratulations to the administrators of the will of $\mathrm{Mr}$. Van Rensselaer, who have so faithfully carried out the purpose of the founder, and to the graduates, who have so well seconded the efforts of these able and conscientious men who have brought the Rensselaer Polytechnic Institute to that great eminence in the public esteem, from which they may look backward with pride and forward in earnest and confident hope of an even brighter and more prosperous future.

WM. MCMurTRIE.

\section{THE RATIONAL BASIS OF MATHEMATICAL PEDAGOGY ${ }^{1}$}

THE rapid development of special methods of teaching special subjects has drawn attention of late to the hitherto neglected field of mathematical pedagogy. The fact that mathematics is the last to respond to improved pedagogical methods is due chiefly to the unusual weight of precedent which attaches to the subject. This inertia of age is, in reality, the chief difficulty to be overcome, for the great antiquity of elementary mathematics and the diversity of the sources from which it originated make it extremely difficult to harmonize the subject with the spirit of modern civilization.

Various plans have recently been proposed for adapting mathematical instruc-

\footnotetext{
${ }^{1}$ Read before American Mathematical Society,
} New York, December 28, 1906. tion to modern conditions, but so far they have been without results of special importance, as no general principle of mathematical pedagogy seems as yet to be recognized. Many of these plans are the results of attempts to meet local conditions and therefore have no general application. Others, however, such as the attempt to correlate mathematics and physics, are intended to stimulate interest in mathematics by establishing more points of contact between it and the other subjects of instruction, thus producing a greater organic unity in the curriculum than has hitherto existed. Such efforts are in line with the constructive and synthetic spirit which characterizes modern scientific thought, and for this reason are worthy of special consideration.

Without going into a detailed analysis of pedagogical methods, it may be well to consider briefly the fundamental principles on which general pedagogy is based, as these principles are well established and apply with peculiar force to mathematics.

The primary consideration in all branches of pedagogy is the aim of education. This has been variously defined, the Herbartian definition of it being that it is "the cultivation of virtue based on many sidedness of interest.', By the cultivation of virtue in this connection must be understood the proper exercise and control of all the faculties. With this understanding the definition fits in, probably as well as any other, with modern ethical and religious ideals. The second half of the definition which bases the development of virtue on the cultivation of wide and varied interests fulfills practical requirements and at the same time affords the proper pedagogical basis for apperception. The most important feature of this definition is that it recognizes both the practical and the cultural aims of education. In other words, it implies that no training can properly be 